\title{
RISK FACTORS AND THEIR IMPACT ON THE STATE OF COLORECTAL ANASTOMOSIS
}

\author{
Cherkasov M.F.', Dmitriev A.V. ${ }^{1}$, Pereskokov S.V. ${ }^{1}$, Kozyrevskiy M.A. ${ }^{1}$, Afunts L.S. ${ }^{1}$ \\ ${ }^{I}$ Rostov State Medical University of the Russian Federation Ministry of Public Health, Rostov-on-Don, e-mail: \\ kozyrevskiy@mail.ru
}

Aims.

The aim of the work was to evaluate the effect of risk factors on the development of leakage of mechanical colorectal anastomosis after surgeries for rectal cancer.

Materials and methods.

The study involved 129 patients who underwent anterior and low anterior resection of the rectum with simultaneous formation of colorectal anastomosis with a circular stapler in the period from 2005 to 2017. The patients' age was 33 to 84 years. Adenocarcinoma of varying differentiation degrees was diagnosed in all cases, but the most common was moderately differentiated tumour - 112 patients $(\mathbf{8 6 . 8 \%})$.

Results.

The overall incidence of anastomotic leak in resection of the rectum was $6.2 \%$, and all cases required active surgical approach. The risk of failure of colorectal anastomosis significantly increased in the presence of adverse factors in the patients: tumour size $\geq 4-5 \mathrm{~cm}$; constrictive nature of the tumour growth; depth of the malignant invasion in the rectal wall; anastomosis localisation in the subperitoneal pelvic segment (low anterior resection); male gender of the patients. Additional strengthening of the mechanical anastomosis defect area with interrupted sutures helped prevent the risk of severe complications. Formation of preventive stomas is indicated after low anterior resection of the rectum in the presence of risk factors.

\section{Conclusions.}

The obtained results suggest that adequate preparation of the segmented intestine, precision mobilisation of the rectum and mesorectum, prevention of the suture line tensioning, compliance with mechanical anastomosis technique, monitoring its tightness, and risk management enables formation of a safe suture and are an important component in the prevention of anastomotic leak.

Keywords: colorectal anastomosis, resection of the rectum, anastomotic leak.

\section{INTRODUCTION.}

Radical surgery is the main stage of combined treatment for colorectal cancer. The main aim of this intervention is not only to follow all the principles of oncologic treatment but also to perform a functionally beneficial sphincter-sparing procedure $[1 ; 2]$. Anterior resection of the rectum was proposed and developed by Dixon in the 1930s. In Russia, the first anterior resection was performed by Petrov in 1937 [3]. In the past decades, this surgery became widespread in all the specialized clinics. Despite the accumulated experience of rectal surgery in the world practice, the rate of postoperative septic complications remains high $(6-25 \%)$ [4; 5]. The main reason for the unsatisfactory outcome is the development of colorectal anastomotic dehiscence (AD) that is observed in 2.5-21\% of cases according to different authors [6;7]. On the one hand, the development and implementation of preventive measures targeted to cope with the specified complications, the use of circumferential staplers, and the formation of preventive intestinal stomas allowed surgeons to improve direct results and functional part of surgical treatment. On the other hand, the study of risk factors and the evaluation of their influence on the outcome of the surgery in each case is an integral part of the scientific search for the solution of the problem of colorectal AD 
after anterior and low anterior resection of the rectum [8; 9]. Despite the vast possibilities of modern surgical techniques that allow for a significant reduction of the rate and severity of postoperative complications, anastomotic dehiscence (AD) can still lead to fatal complications [10]. The fact that it is impossible to predict the development of $\mathrm{AD}$ before the surgery and its diagnostics in the early postoperative period decreases the effectiveness of preventive measures and leads to late treatment of the developed complications. In the present study, the authors analyzed the clinical material on this problem and the risk factors that influence the direct outcome of the treatment in patients that underwent resection of the rectum with simultaneous formation of colorectal anastomosis.

The study was aimed to evaluate the influence of the risk factors on the development of mechanical colorectal AD after the surgery for colorectal cancer.

MATERIALS AND METHODS. The authors performed a retrospective analysis of 129 patients that underwent anterior and low anterior resection of the rectum with simultaneous formation of colorectal anastomosis with a circumferential stapler in 2005-2017.

The study protocol followed guidelines for experimental investigation with human subjects in accordance with the Declaration of Helsinki and was approved by the ethics committee. Written informed consent was obtained from each patient (or an official representative) before the study.

The characteristic of patients by sex and age depending on the volume of surgical intervention is presented in Table 1. The patients' age varied from 33 to 84 years old. There were more women in the study. For the evaluation of the level of the formation of colorectal anastomosis on its dehiscence, the patients were divided by this criterion.

Table 1. Characteristics of patients by sex, age, and level of resection

\begin{tabular}{|c|c|c|c|c|}
\hline \multirow{2}{*}{ Age group } & \multicolumn{2}{|c|}{ Low anterior resection of the rectum } & \multicolumn{2}{l|}{ Anterior resection of the rectum } \\
\cline { 2 - 5 } & Male & Female & Male & Female \\
\hline $31-40$ & - & 1 & - & 3 \\
\hline $41-50$ & 3 & 6 & 7 & 5 \\
\hline $51-60$ & 1 & 9 & 8 & 9 \\
\hline $61-70$ & 10 & 9 & 8 & 11 \\
\hline $71-80$ & 6 & 2 & 1 & - \\
\hline $81-90$ & 3 & 40 & 23 & 31 \\
\hline Total (men/women) & 23 & & \\
\hline
\end{tabular}

In all the cases, adenocarcinoma of different degrees of differentiation was diagnosed. In the majority of cases (112 patients, 86.8\%), moderately differentiated tumor was revealed. The localization of the tumor in the rectum is presented in Table 2.

Table 2. Localization of the primary tumor.

\begin{tabular}{|c|c|c|}
\hline & \multicolumn{2}{|c|}{ Number of patients } \\
\hline Localization of the primary tumor & $\begin{array}{c}\text { Abs. number } \\
(\mathbf{n = 1 2 9})\end{array}$ & 19.3 \\
\hline The lower third of the ampulla & 25 & 29.4 \\
\hline The middle third of the ampulla & 38 & \\
\hline
\end{tabular}


The upper third of the ampulla, the rectosigmoid juncture

The characteristic of the tumor by the degree of invasion into the intestinal wall by the group of patients is presented in Table 3 .

Table 3. Characteristics of the tumor in the surgical groups

\begin{tabular}{|c|c|c|}
\hline $\begin{array}{c}\text { Characteristics of the } \\
\text { tumor }\end{array}$ & Low anterior resection & Anterior resection \\
\hline T2 & 22 & 18 \\
\hline T3 & 41 & 42 \\
\hline T4a & - & 6 \\
\hline Total & 63 & 66 \\
\hline
\end{tabular}

Comorbid diseases were revealed in all the patients in different degrees of compensation (Table 4).

Table 4. Comorbid diseases in patients.

\begin{tabular}{|l|c|c|}
\hline \multirow{2}{*}{$\begin{array}{l}\text { Comorbid diseases in patients with } \\
\text { colorectal cancer }\end{array}$} & Abs. & Total number of patients (n=129) \\
\cline { 2 - 3 } & 109 & 84.4 \\
\hline $\begin{array}{l}\text { Cardiac pathology (IHD, arterial } \\
\text { hypertension, etc.) }\end{array}$ & & 34.1 \\
\hline Diabetes mellitus, compensation & 44 & 34.8 \\
\hline Diverticulosis & 45 & 30.2 \\
\hline $\begin{array}{l}\text { Bronchopulmonary pathology } \\
\text { (COPD, obstructive bronchitis, } \\
\text { etc.) }\end{array}$ & 39 & \\
\hline
\end{tabular}

The mean body mass index (MBI) was $24.2 \pm 3.4 \mathrm{~kg} / \mathrm{m}^{2}$ and was within the range from 16.4 to $33.4 \mathrm{~kg} / \mathrm{m}^{2}$. In 8 patients with obesity, lower anterior resection of the rectum was performed. In 7 cases, the anastomosis was localized $10 \mathrm{~cm}$ superior to linea anocutanea.

The results of the laboratory parameters revealed anemia in 83 patients (64.3\%), the level of hemoglobin varied from 72 to $118 \mathrm{~g} / \mathrm{L}$. Patients with anemia of the 2 nd-3rd degree (12 patients, $14.4 \%$ ) needed blood transfusion in the postoperative period. Taking into account the fact that the level of albumin in blood influences the healing of anastomosis, the authors controlled this parameter. In the postoperative period, 23 patients had hypoalbuminemia, i.e. the content of protein was less than $28 \mathrm{~g} / \mathrm{L}$, which required profound correction in the postoperative period.

The anastomosis was classified as low when it was located from $10 \mathrm{~cm}$ and inferior to the dentate line [7]. The lower pole of the tumor in patients from the studied groups was located 6.0$15.5 \mathrm{~cm}$ from the anorectal line. The distal edge of the resection was $2 \mathrm{~cm}$ caudal to the lower border of the tumor. Patients with low anterior resection of the rectum underwent total mesorectal excision with precision isolation of the interfascial layer.

In 104 patients $(80.6 \%)$, the rectal stump was formed with the apparatus "Contour" (Ethicon, 
USA), in the rest cases, the sutures were made manually. The colorectal anastomosis was formed end-to-end with a circumferential stapler of the required diameter $(29.31 \mathrm{~mm})$. After the formation of anastomosis, air testing of the sealed sutures was performed. The mean duration of the surgery was 165.2 \pm 32.1 (124-360 minutes). The longest duration of surgery was in patients with low anterior resection. However, there was no significant difference in the duration depending on the level of anastomosis location $(\mathrm{p}=0.625)$.

In 46 patients with lower anterior resection of the rectum and 36 patients with anterior resection of the rectum, mobilization of the splenic flexure was performed in cases of unsatisfactory arterial blood flow in the marginal vessel or insufficient length of the descending colon. In 44 patients $(34.1 \%)$, the inferior mesenteric artery was clamped and dissected distally to the bifurcation of the left colic vessel. In 23 patients (17.8\%), intrahepatic metastases were diagnosed, which led to one-step combined surgery with the resection and/or local thermal destruction of intrahepatic tumor nodes. In 10 cases, such patients underwent lower anterior resection of the rectum. In the rest 13 cases, anterior resection of the rectum was performed.

In 14 patients, atypical resection of the right liver lobe was performed. Five patients underwent segmentectomy SV-SVI. In 10 cases, the resection of 2 to 4 metastatic nodes was performed, in 1 case, atypical resection of both liver lobes was performed. The diameter of nodes varied from 35 to $70 \mathrm{~mm}(45 \pm 3.1 ; \mathrm{Me}=47)$. The rest 9 patients with intrahepatic metastases underwent radiofrequency thermoablation of the tumor nodes that varied from 18 to $38 \mathrm{~mm}$ $(27.1 \pm 1.4 ; \mathrm{Me}=28)$.

The volume of blood loss varied from 240 to $1550 \mathrm{ml}(440 \pm 178.3)$ and depended on the volume of the surgical intervention. Intraoperative donor blood transfusion was performed to 16 patients $(12.4 \%)$. Eleven from these patients underwent combined respective manipulations on the liver.

After the surgery, 80 patients $(62 \%)$ underwent pelvic peritoneum repair. In all the cases, the pelvic cavity was drained via the contraincision in the anterior abdominal wall.

\section{RESULTS.}

In 8 cases (6.2\%), AD was diagnosed on Days 3 to 7. Patients developed clinical signs of peritonitis. The intestinal discharge was observed in the drainage. In 5 cases (7.9\%), AD developed after lower anterior resection of the rectum, in 3 cases $(4.5 \%)$ - after anterior resection. The rate of $\mathrm{AD}$ was significantly higher in patients after low anterior resection of the rectum $(\mathrm{p}=0.324)$.

The analysis of the AD causes showed that it primarily occurred in men (5 patients) and patients aged 61-80 years old (4 patients). In 2 patients with $\mathrm{AD}$, the volume of intraoperative loss was more than $700 \mathrm{ml}$, which required donor blood and plasma transfusion. The multifactor analysis revealed that the volume of blood loss and intraoperative blood transfusion did not influence significantly the occurrence of $\operatorname{AD}(p=0.633)$. At the same time, male sex was an independent significant risk factor $(\mathrm{p}=0.344)$. 
The tumor size (more than 4-5 cm), circular growth, and the degree of its ingrowth into the intestinal wall also showed to be risk factors in the development of AD. The results of pathomorphological studies of the remote specimens obtained from patients with AD revealed tumor ingrowth into all the intestinal layers to the subserosa and, in some cases, to the visceral peritoneum or visceral layer of the pelvic fascia.

Such parameters as BMI, diabetes mellitus, the duration of the operation, the diameter of the stapler, the level of the clamping of the superior mesenteric artery, and combined operations did not show to have a significant influence on the occurrence of AD in the present study ( $p=0.778$ ).

The intraoperative blood loss in patients after the resection of the rectum varied from 240.0 to $710.0 \mathrm{ml}(433.3 \pm 91.1 \mathrm{ml})$. The duration of the operation was 147 to 243 minutes $(168 \pm 56.5$ minutes). In patients who underwent combined operations, the blood loss was 845.9 to $1550.0 \mathrm{ml}$ $(1330 \pm 98.0 \mathrm{ml})$ when the operation lasted 190 to 284 minutes ( $248 \pm 47.3$ minutes). The parameters of the duration and intraoperative blood loss in patients with simultaneous manipulations on the liver were significantly higher in patients that had only primary tumor resection $(p<0.0001)$. Still, the data analysis did not reveal a significant difference in the influence of the operation duration and the volume of the blood loss on the occurrence rate and severity of the postoperative complications, including the risk of the development of $\mathrm{AD}(\mathrm{p}=0.695)$.

Repeated interventions were performed to all 8 patients with AD. In 6 cases, it included the removal of the anastomosis and end colostomy exteriorization. In 2 cases, additional sutures were placed on the defected area and preventive colostomies were exteriorized.

It should be mentioned that there were 5 intraoperative cases $(7.9 \%)$ when patients with low anterior resection of the rectum had preventive stomas formed. In 1 case (1.5\%), the colostomy was exteriorized with the formation of the anastomosis $10 \mathrm{~cm}$ superior to linea anocutanea. The period of restoration of intestinal continuity varied from 2 to 6 months. The main reason for the formation of preventive stomas (5 cases) was a positive insufflation test during the evaluation of the junction sealing. For the sealing of the anastomosis, the defected area was additionally sealed with remote seromuscular sutures. In 1 case, the stoma was made due to the prognosis of possible AD because of the risk factors: significant difference in the diameter of the sutured ends, insufficient preparation, expressed alimental deficiency, and the infiltrative process in the mesorectum. In the postoperative period, these patients did not have events of colorectal AD.

To avoid the tensioning of the proximal sections of the colon, 44 patients with low localization of the tumor underwent mobilization of the splenic flexure and, in 36 patients, it was done with the localization of the anastomosis $10 \mathrm{~cm}$ superior to the anorectal line. Still, it should be mentioned that this stage of the surgery was not obligatory and was performed when necessary. According to the available published data, one of the risk factors for AD is the period of drainage of pelvic organs $[5 ; 11]$. In the present study, the drainage tubes were removed after the first defecation on Days 3-6 provided there was no pathological discharge. 
The lethal outcome was registered in 3 cases. In 2 cases, it was caused by AD after anterior resection with further complications that required multiple relaparotomy interventions and led to the development of multi-organ failure. In 1 case, it was caused by pulmonary artery thromboembolism in spite of the performed preventive measure before and after the surgery.

The results of the present study showed an increase in the occurrence rate of AD after low anterior resection of the rectum. In patients with several risk factors and prognosis for the possible occurrence of $\mathrm{AD}$, a preventive stoma should be exteriorized. The authors did not reveal any significant differences in the rate of colorectal AD depending on the method of rectal stump sealing: manual sutures or with a stapler. There was no significant difference either in the influence of the duration of the surgery, the volume of the blood loss, and intraoperative blood transfusion. A retrospective analysis and the obtained results of the study showed that adequate preparation of the segmented intestine, a precision technique of the rectum and mesorectum mobilization, prevention of the suture tensioning, following the protocol of the mechanical anastomosis formation, control of its sealing, and consideration of the risk factors provide a reliable suture and an important part of the prevention of AD. The period of drainage of pelvic organs should last not less than 2-3 days after the patient's first defecation.

\section{CONCLUSIONS.}

1. The occurrence rate of $\mathrm{AD}$ in patients with the resection of the rectum was $6.2 \%$ and required active surgical tactics in all the cases.

2. The risk of AD development significantly increased in patients with unfavorable factors: tumor size $\geq 4-5 \mathrm{~cm}$; obstructive tumor growth, depth of the tumor ingrowth into the rectal walls, localization of the anastomosis in the subperitoneal area of the pelvis (low anterior resection), and male sex.

3. Additional enforcement if the defected area of the mechanical anastomosis with interrupted node sutures prevents the development of severe complications. The formation of the preventive stomas is necessary after low anterior resection of the rectum in patients that are exposed to risk factors. The stoma itself does not increase the risk of the development of AD.

\section{FINANCIAL SUPPORT AND SPONSORSHIP}

Nil.

\section{CONFLICTS OF INTEREST}

The authors declare no conflict of interest

\section{SUPPLEMENTARY DATA (DOI)}




\section{REFERENCES}

1. Cherdantsev D.V., Pozdniakov A.A., Shpak V.V. et al. Colorectal anastomotic failure. current state of the problem (study review) [Nesostoiatel'nost' kolorektal'nogo anastomoza. Sovremennoe sostoianie problemy (obzor literatury)]. Coloproctology - Koloproktologiia, 2015, vol. 54, no 4, pp. 57-64.

2. Cherkasov M.F., Dmitriev A.V., Groshilin V.S. et al. Experience of surgical treatment of colorectal cancer with liver metastases. [Opyt khirurgicheskogo lecheniia kolorektal'nogo raka s metastazami v pechen']. Coloproctology - Koloproktologiia. 2017, vol. 60, no 2, pp. 45-52.

3. Shatrova N.A. Prediction, prevention and treatment of colonic anastomoses insolvency: the dissertation of the candidate of medical sciences [Prognozirovanie, profilaktika i lechenie nesostoiatel'nosti tolstokishechnykh anastomozov: dissertatsiia kandidata meditsinskikh nauk]. Perm, 2012, $130 \mathrm{p}$.

4. Agaev E.K The intestinal anastomotic insufficiency after the emergency gut resection [Nesostoiatel'nost' shvov kishechnykh anastomozov u bol'nykh posle ekstrennoi i neotlozhnoi rezektsii kishki]. Pirogov Russian Journal of Surgery - Khirurgiya. Zhurnal imeni N.I. Pirogova, 2012, no 1, pp. 34-37.

5. Popov D.E. Risc factors of anastomotic leakage in patients with rectal carcinoma [Faktory riska nesostoiatel'nosti kolorektal'nykh anastomozov u bol'nykh rakom priamoi kishki] Coloproctology Koloproktologiia, 2014, vol. 48, no 2, pp. 48-56.

6. Polovinkin V.V., Prokhanov V.A., Zavrazhnov A.A. et al. Risk factors for colorectal anastomosis insolvency following rectal cancer surgery [Faktory riska razvitiia nesostoiatel'nosti kolorektal'nogo anastomoza posle operatsii po povodu raka priamoi kishki] Kuban Scientific Medical Bulletin Kubanskii nauchnyi meditsinskii vestnik, 2013, no 7, pp. 106-112.

7. Yang L., Huang X.E., Zhou J.N. Risk Assessment on Anastomotic Leakage after Rectal Cancer Surgery: An Analysis of 753 Patients. Asian Pacific Journal of Cancer Prevention, 2013, vol. 14, no 7, pp. 4447-4453, doi 10.7314/apjcp.2013.14.7.4447.

8. Giaccaglia V., Salvi P.F., Cunsolo G.V. et al. Procalcitonin, as an early biomarker of colorectal anastomotic leak, facilitates enhanced recovery after surgery. Journal of Critical Care, 2014, vol. 29, no 4, pp. 528-532, doi 10.1016/j.jcrc.2014.03.036.

9. Hayden D.M., Pinzon M.C., Francescatti A.B. et al. Patient factors may predict anastomotic complications after rectal cancer surgery Anastomotic complications in rectal cancer. Annals of Medicine and Surgery, 2015, vol. 4, no 1, pp. 11-16, doi 10.1016/j.amsu.2014.12.002.

10. Ermakov D.F. Hardware anastomosis insolvency risk factors after anterior rectal resection: the dissertation of the candidate of medical sciences [Faktory riska nesostoiatel'nosti apparatnogo anastomoza posle perednei rezektsii priamoi kishki: dissertatsiia kandidata meditsinskikh nauk]. Moscow, 2012, 24 p. 
11. Linev K.A., Vysotskii A.A. Tactics of surgical treatment of failure of large intestine anastomosis sutures [Taktika khirurgicheskogo lecheniia nesostoiatel'nosti shvov anastomoza tolstoi kishki]. Bulletin of Urgent and Restorative Medicine - Vestnik neotlozhnoi $i$ vosstanovitel'noi meditsiny, 2013, vol. 14, no 4, pp. 474-477. 